\title{
ANÁLISE DE CABECEIRAS DE DRENAGEM A PARTIR DE CLASSIFICAÇÃO GEOSSISTÊMICA E DA RELAÇÃO HIPSOMETRIA- DECLIVIDADE EM UNIDADE DE PAISAGEM INSERIDA NA BACIA DO CELMM
}

\author{
Raquel Lourenço da Silva ${ }^{(a)}$, Kadja Monaysa Mendonça de Paula ${ }^{(b)}$, Kleython de Araújo \\ Monteiro $^{(\mathrm{c})}$ \\ (a) UFAL, raquellourenco.rls@ gmail.com \\ (b) UFAL, kay_mmp@ @otmail.com \\ (c) UFAL, geokleython@gmail.com
}

Eixo: Uso e ocupação das terras e legislação ambiental

\begin{abstract}
Resumo
O presente trabalho tem como finalidade a análise geossistêmica, hipsométrica e de declividade de cabeceiras de drenagem em unidade de paisagem inserida na Bacia do Complexo Estuarino Lagunar Mundaú Manguaba (CELMM). A partir desta análise pôde-se definir a relação entre os principais tipos de uso de solo na área e suas principais ocorrências ambientais.
\end{abstract}

Palavras-chave: Cabeceiras de drenagem. Unidade de paisagem. Bacia do Celmm.

\section{Introdução}

A teoria de geossistemas de Sochava (1977), a qual define unidades naturais de dimensão qualquer que integra uma entidade de dimensão maior, apresenta termos bastante complexos, esses que auxiliam na classificação dos geossistemas quanto sua estrutura (geômeros) e suas qualidades integrativas (geócoros).

De acordo com Cavalcanti (2014) o termo geômero trata de uma classificação de paisagem com base numa tipologia, uma categoria estrutural homogênea. Já o termo geócoro de uma classificação baseada na integralização espacial de determinada paisagem, uma associação espacial de caráter único.

Essa classificação será tratada no presente trabalho com o estudo de cabeceiras de pequenas drenagens, essas que se caracterizam por desenvolver-se nas encostas e por apresentarem topografias côncavas, originando as cabeças de canais. O termo "cabeceira de drenagem" é tratado na literatura internacional por Hack como "hollow" e no Brasil de "rampa" por Meis \& Monteiro ou "concavidade" por Avelar \& Coelho Netto (Coelho Netto, 2013). 
Neste sentido, o presente estudo tem o objetivo de analisar a hipsometria e declividade de cabeceiras de drenagem da Bacia do Complexo Estuarino Lagunar Mundaú Manguaba (CELMM) e classificar a referida unidade geossistêmica em geômeros e geócoros, a fim de identificar as limitações e potencialidades para o uso do solo. Para isso, têm-se como objetivos específicos mapear e quantificar as diferentes classes hipsométricas e de declividade, fazer a correlação com as atividades de uso do solo na área e os problemas ambientais estimulados por essas ações.

\section{Caracterização da Área}

A Bacia do CELMM abrange uma área de $3.151 \mathrm{~km}^{2}$, com 12 municípios e uma população de 1.228 .773 habitantes, os rios integrantes da bacia são: Rio Sumaúma, Rio Estivas, Rio Remédios, Riacho do Silva, Rio Mundaú e Rio Paraíba do Meio, esses que contribuem para o complexo que dá nome a bacia.

A área em estudo está localizada entre os municípios de Coqueiro Seco e Santa Luzia do Norte, Alagoas. Encontra-se geologicamente inserida na Província Borborema, representada pelos litólitos da Formação Muribeca-Membro Carmópolis, grupo Barreiras e Depósitos Flúvio-Lagunares. Seu relevo faz parte da unidade dos Tabuleiros Costeiros e apresentam solos em geral profundos e de baixa fertilidade natural. O clima é do tipo tropical chuvoso com verão seco, a precipitação média anual é de $1.634 \mathrm{~mm}$. A vegetação é predominante do tipo floresta subperenifólia, com partes de floresta subcaducifólia.

\section{Metodologia}

Para desenvolvimento deste trabalho foi realizada uma vasta revisão bibliográfica no que refere-se as temáticas abordadas, como: cabeceiras de drenagem, classificação geossistêmica, hipsometria e declividade.

Além disso, foram geradas, em ambiente GIS, cartas de relevo e uso do solo, hipsometria e declividade, para posterior análise desses componentes na unidade de paisagem examinada. Para isso, no ambiente GIS foi digitalizada a Carta Topográfica Matricial do município de Pilar-Alagoas publicada em 1985, folha SC-25-V-C-IV-1-50, na escala de 1:50.000, onde foram geradas em formato de linhas as curvas de nível, bem como, em formato de polígono, a limitação da laguna Mundaú, as unidades de relevo, cultura existente e a drenagem que se apresenta nesta área de estudo. As linhas da curva de nível que foram geradas, deram base para a criação das cartas hipsométrica e de declividade. 
Na geração da carta hipsométrica, pela amplitude altimétrica presente na área de estudo, foram criadas dez classes de altitude, cada qual com nove metros de amplitude, as quais são: 1-10; 11-20; 21-30; 31-40; 4150; 51-60; 61-70; 71-80; 81-90; 91-100.

Já para o mapa de declividade foram elaboradas cinco classes com diferentes porcentagens de declive, sendo: $5 \%$ para plano; $16 \%$ para suave ondulado; $28 \%$ para ondulado; $45 \%$ para forte ondulado; $100 \%$ para escarpado. Para o mapa de unidades de revelo, foram criados polígonos para as diferentes morfologias, sendo estas: topo; encosta; base. E com esta mesma carta topográfica, foi possível delimitar as culturas presentes, para traçar um perfil do uso e ocupação do solo.

Após, realizou-se a classificação geossistêmica dessa unidade de acordo com a abordagem proposta por Sochava (1977) em seu trabalho $O$ estudo de geossistemas, onde foram observadas a tipologia e associação espacial presente para determinação dos ambientes de ocorrência de geômeros e geócoros, respectivamente.

\section{Resultados e Discussões}

A área em estudo apresenta um amplo espaço compreendido por encostas, abrangendo o município de Santa Luzia do Norte a Coqueiro Seco, Alagoas, que são formadas por voçorocas estabilizadas que originam as cabeceiras de drenagem. Portanto, por serem voçorocas, esta área está suscetível ao processo erosivo, por eventual desequilíbrio ambiental que possa vir ocorrer.

Como mostra na figura 1, as unidades de relevo, como: topo, encosta e base; apresentam-se com cultura temporária, com o cultivo de cana-de-açúcar, nestas três unidades de relevo, e com cultura permanente, com cultivo de coco, no início da encosta e, em maior escala, na base. Formando assim, geômeros na parte compreendida por: topo e cultura temporária; encosta e cultura temporária; base e cultura temporária; encosta e cultura permanente; base e cultura permanente. Com cada um desses tendo o seu próprio mecanismo de fluxo de energia e matéria, compondo um geócoro. 


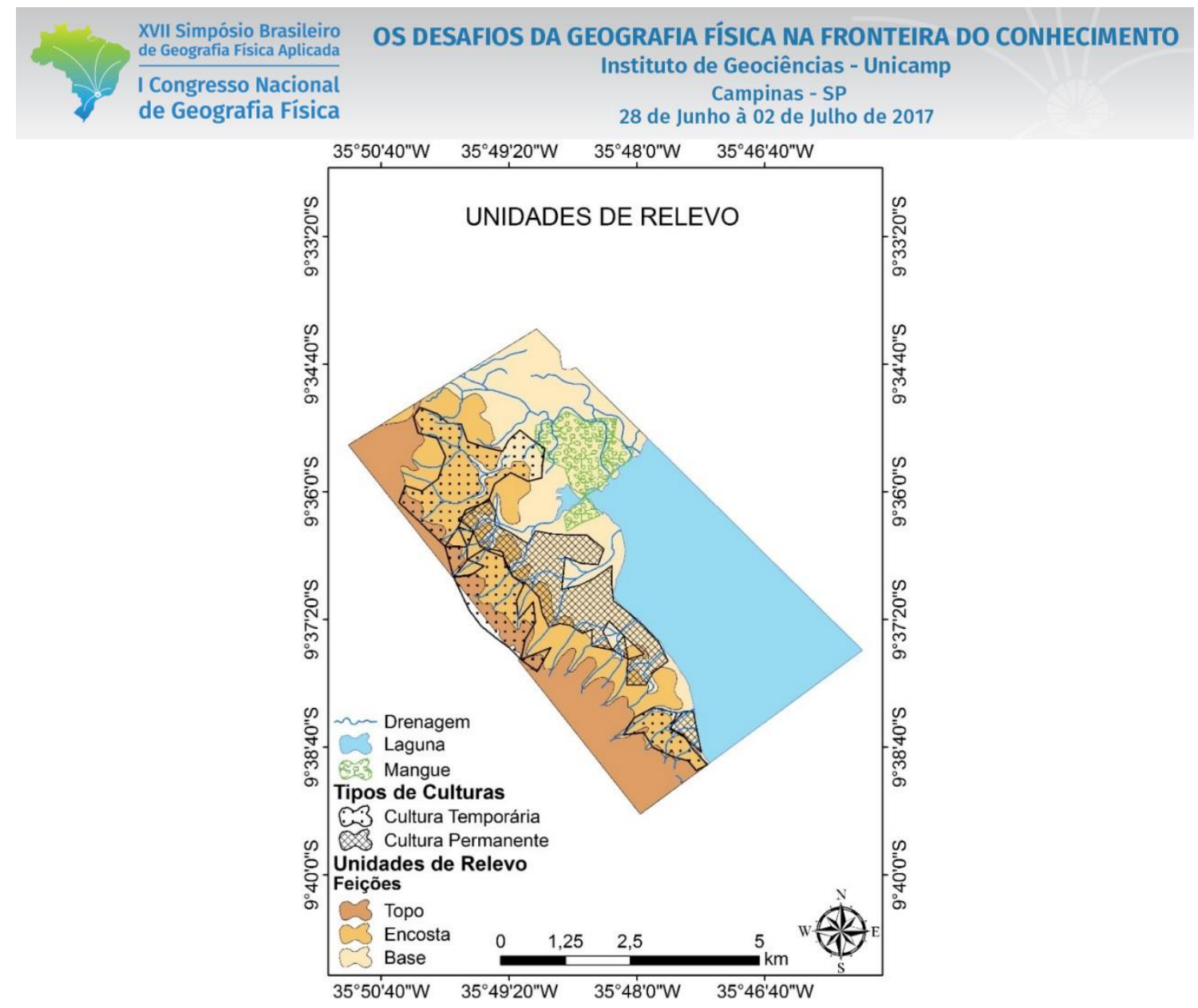

Figura 1 - Unidades de relevo e tipos culturas da área de estudo.

Observa-se na carta hipsométrica (figura 2) que a altimetria apresentada na área varia de 1 a 100 metros, onde no topo vamos encontrar uma altitude que vai varia de 91 a 100 metros. Já na encosta apresentou uma variação de 21 a 90 metros e na base uma variação média de 11 a 20 metros. Apresentando assim, uma amplitude altimétrica significativa onde se localizam os geômeros desta área, que pode apresentar um processo erosivo em cada unidade de relevo, devido ao uso e ocupação do solo. Pois, como o topo é compreendido pelo cultivo de cana-de-açúcar, e por estar em uma área suscetível ao desencadeamento do processo erosivo, essa área se torna instável devido ao avanço do cultivo na encosta, podendo causar assoreamento dos canais que se formam nas cabeceiras. 


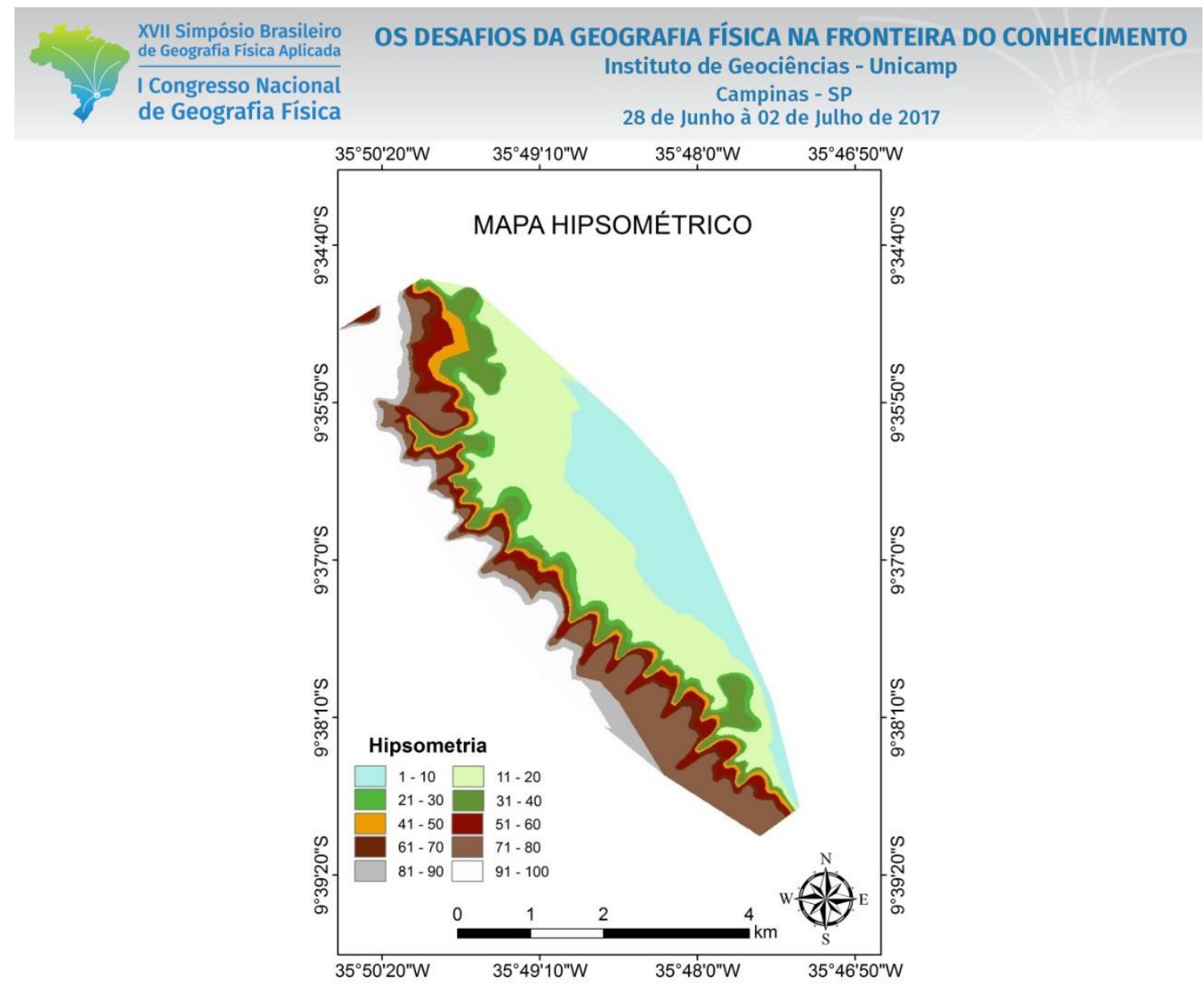

Figura 2 - Amplitude altimétrica da área de estudo.

No mapa de declividade (figura 3), demostrou que as áreas com declive mais frequente e acentuado, se localizam na encosta, parte que é compreendida por geômeros. A área da encosta compreende as feições: suave ondulado, ondulado, forte ondulado e escarpado. O resultado dessa formação, é que as áreas com declive muito acentuado, o cultivo da cultura presente pode ser comprometido, pois, esta área é mais suscetível a deslizamentos e processos erosivos. As áreas com feições forte ondulado e escarpado compromete o manejo, impedindo assim, o cultivo de culturas como a de coco e cana-de-açúcar. 


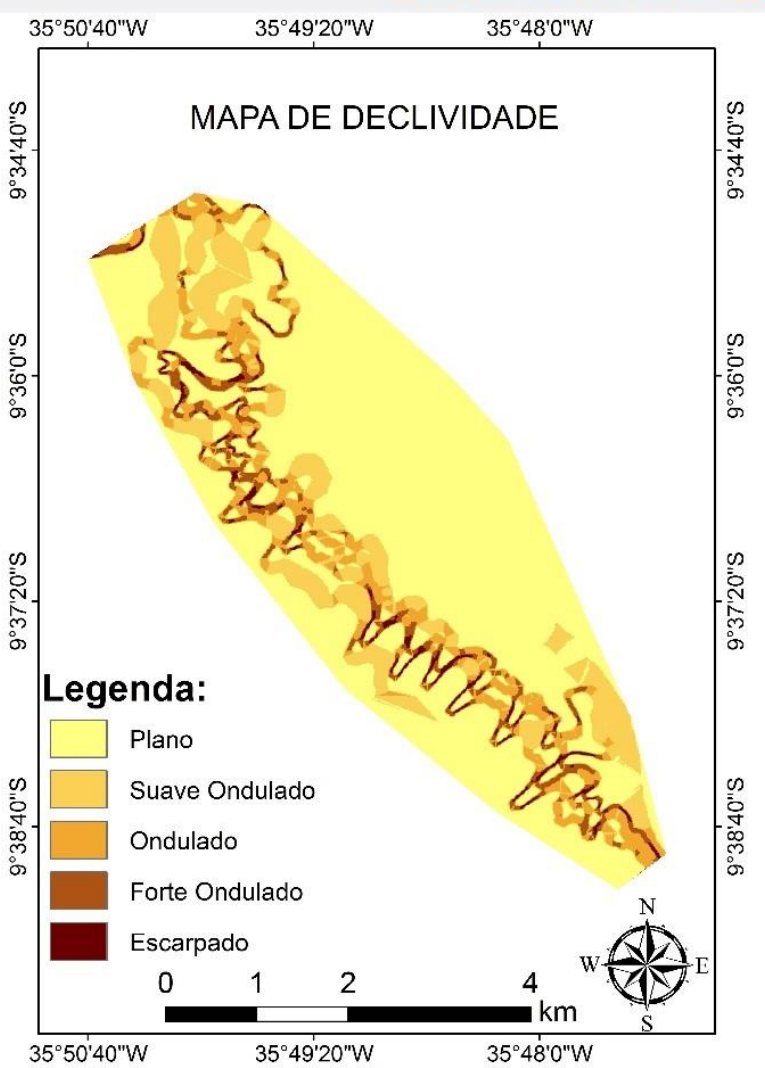

Figura 3 - Declividade da área de estudo.

\section{Considerações Finais}

Com este trabalho foi possível subdividir as classes presentes dos geômeros encontrados na área de estudo. Os que apresentaram maior instabilidade foram os que se situaram na encosta, áreas quais apresentaram maior declividade, que se situam entre as faixas hipsométricas de 70 a 21 metros.

\section{Bibliografia}

CAVALANTI, L. C. S. Geômeros ou geócoros? Petrolina: UPE.2014. Notas de aula. Disponível em: www.cartadepaisagem.blogspot.com/p/material.html.

COELHO NETTO, A. L. Evolução de Cabeceiras de Drenagem no Médio Vale do Rio Paraíba do Sul (SP/RJ): a Formação e o Crescimento da Rede de Canais sob Controle Estrutural. Revista Brasileira de Geomorfologia, Ano 4, No 2 (2003). 69-100 p.

PEREIRA, A. A.; THOMAZ, E. L. Hipsometria e declividade da Bacia Hidrográfica do Arroio Palmeirinha, município de Reserva - PR, utilizando o Software Spring. Anais...XVI Simpósio Brasileiro de Sensoriamento Remoto, Foz do Iguaçu, PR. 2013. 3494-3501 P. 


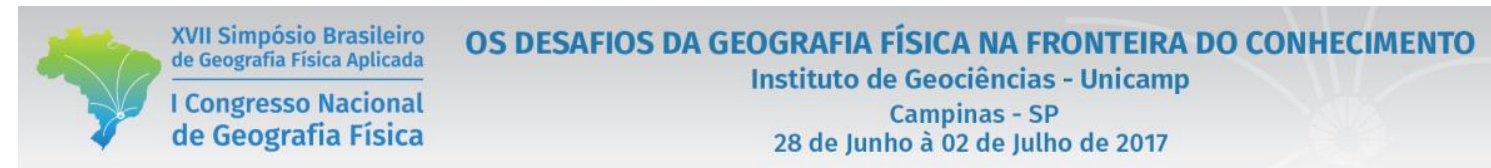

SOCHAVA, V. B. O estudo de geossistemas. Métodos em questão, n.16, IGUSP. São Paulo, 1977. 51 p. 